
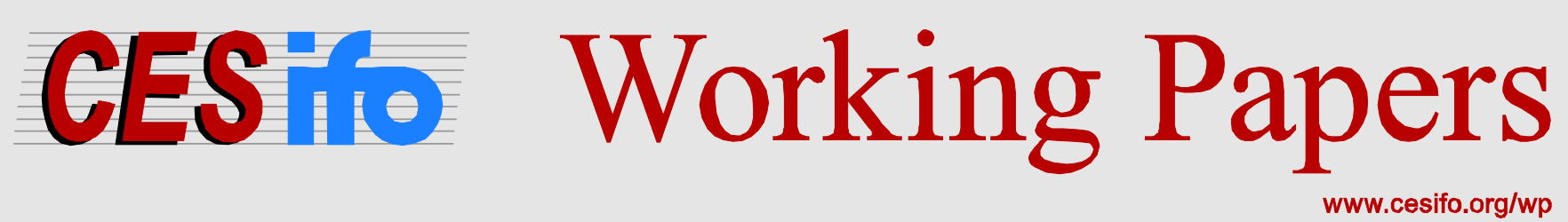

\title{
Fiscal Transfers in a Monetary Union with Exit Option
}

\author{
Carsten Hefeker \\ Michael Neugart
}

\author{
CESIFO WORKING PAPER NO. 5244 \\ CATEgORy 7: MONETARy POLICY AND INTERNATIONAL FinANCE \\ MARCH 2015
}

An electronic version of the paper may be downloaded

- from the SSRN website:

- from the RePEc website:

- from the CESifo website: www.SSRN.com

www.RePEc.org

www.CESifo-group.org/wp

\section{CESifo}




\title{
Fiscal Transfers in a Monetary Union with Exit Option
}

\begin{abstract}
It is widely debated whether a monetary union has to be accompanied by a fiscal transfer scheme to accommodate asymmetric shocks. We build a model of a monetary union with a central bank and two heterogeneous countries that are linked by a fiscal transfer scheme with repercussions on monetary policy. A central bank aiming at securing the existence of a monetary union in the presence of asymmetric shocks has to compensate single countries for the tax distortions arising from fiscal transfers. Monetary policy may become more expansionary or restrictive depending on asymmetries between member countries' inflation aversion and exit costs.
\end{abstract}

JEL-Code: E520, E630, F330.

Keywords: monetary union, fiscal transfer scheme, monetary policy, asymmetric shocks, exit.

Carsten Hefeker

FoKoS, University of Siegen

Germany-57068 Siegen

carsten.hefeker@uni-siegen.de
Michael Neugart

Technical University of Darmstadt

Germany - 64283 Darmstadt

neugart@vwl.tu-darmstadt.de

February 2015 


\section{Introduction}

As a response to the financial crisis and its implications for sovereign debt, members of the European Monetary Union (EMU) strive for policy measures to reassure the functioning of the Stability and Growth Pact (SGP). Efforts at reform resulted in the so called "Fiscal Compact" in which signatories agreed to implement balanced budget rules in their countries, preferably of a constitutional character, install automatic correction mechanisms for excessive deficits and debt levels, and reinforce coordination of fiscal policies. ${ }^{1}$

On top of these reforms, calls for further steps to integrate European fiscal policy have been made. One example is the statement by the former President of the European Council, Herman van Rompuy, that "In the longer term, there is a need to explore the option to go beyond the current steps to strengthen economic governance by developing gradually a fiscal capacity of the EMU. Such a fiscal capacity could take several forms and various options would need to be explored". He continues to suggest that "One of the functions of such a new fiscal capacity could be to facilitate adjustments to country specific shocks by providing for some degree of absorption at the central level...Asymmetric shock absorption at the central level would represent a form of limited fiscal solidarity exercised over economic cycles, improving the economic resilience of the EMU." 2

Potential consequences of such a fiscal transfer scheme for Europe are discussed in the literature stressing that although these schemes allow for pooling risk among member states they may also cause problems of moral hazard (Persson and Tabellini, 1996a) and redistribute income (Persson and Tabellini, 1996b). For Europe, Bargain et al. (2013) simulate the economic effects of an EU-wide tax and transfer system and a fiscal equalization mechanism finding that fiscal stabilization is accompanied by significant redistributive effects. An aspect typically neglected in these discussions, however, are the potential repercussions that a fiscal transfer scheme may have on central bank behavior and inflation. In particular, it is an open question what kind of monetary policies a fiscal transfer scheme triggers in a union in which the central bank has a vital interest in securing its own existence and ensuring the continuation of the monetary union. This is where we add to the current discussion.

We build a model of a monetary union with a central bank and two heterogeneous member states in the presence of a fiscal insurance scheme. Member states are linked by a fiscal transfer mechanism that is activated as the union is hit by an asymmetric shock. The member country negatively affected receives a transfer from the other member state. In order to keep the government budget balanced the giving country has to increase distortionary taxes which depresses output in this country. Countries face the decision to stay within the mone-

\footnotetext{
${ }^{1}$ The official name of the "Fiscal Compact" is The Treaty on Stability, Coordination and Governance (TSCG) signed by the leaders of all Euro Area member states and eight other EU member states on March 2nd 2012. It entered into force on January 1st, 2013.

${ }^{2}$ See "Toward a genuine Economic and Monetary Union", Interim Report, The President of the European Council, Brussels, 12 October 2012, p.4.
} 
tary union which implies paying (or receiving) the transfer and being subject to the monetary policy decision of the common central bank, or to leave the union which imposes exit costs but would allow for a monetary policy tailored to national needs.

Given that either country may decide to exit the union, a central bank having a vital interest in securing the monetary union will have to react appropriately to avoid a break-down. We show that monetary policy making may become expansionary or more restrictive depending on the inflation aversion and the exit costs of the country closer to exiting the monetary union. In a homogenous union, the contributing country will want to be compensated by the central bank through higher inflation rates or it will exit the union. In a heterogeneous union monetary policies may go either way. With a fiscal transfer scheme monetary policy becomes more expansionary only if the giving country has lower expected exit costs or a lower inflation aversion than the country receiving the transfer. Monetary policy becomes more restrictive with a fiscal transfer scheme if the giving country has sufficiently high expected exit costs or sufficiently high inflation aversion.

The paper is structured as follows. The next section relates our setup to the literature while section 3 develops the model. Section 4 derives optimal behavior of governments and central bank, and section 5 concludes.

\section{Literature review}

Our discussion is related to the literature in several ways. First, the argument that a monetary union has to be accompanied by a fiscal insurance scheme is part of the optimum currency area literature (for a recent survey, see Tavlas 2009). Kenen (1969) argued that countries should only give up monetary autonomy if fiscal policy would compensate for the stabilizing role of monetary policy. Asymmetric shocks could be accounted for if there was a redistribution system that would channel fiscal funds from those regions or countries experiencing positive shocks to those negatively affected. The boundaries of optimum currency areas are thus drawn by fiscal integration. Consequently, the early academic discussion of the EMU project concentrated on deriving the empirical need for fiscal redistribution among European member states and comparing it with existing other federal monetary unions, such as the US or Canada. The conclusion usually was that Europe is far too less fiscally integrated to form an optimum currency area (Bayoumi and Masson 1995; Eichengreen 1990; Sala-iMartin and Sachs (1991); Von Hagen 1991).

Second, however, the Delors report in 1989, providing the blueprint for the EMU, initiated a debate on the dangers and negative consequences of fiscal integration. ${ }^{3}$ Scholars became aware that a common central bank for Europe

\footnotetext{
${ }^{3}$ Report on economic and monetary union in the European Community, presented April, 17, 1989, by the Committee for the Study of Economic and Monetary Union, Jacques Delors (Chairman). A comprehensive survey of the more recent literature on this topic is given in Beetsma and Giuliodori (2010).
} 
with national fiscal policies would change the way one would have to think about the interaction of fiscal and monetary policy making. Goodhart (1998, p. 425) noted that "In the Euro area, the traditional historical links between money creation and sovereignty will be broken to a unique extent." Most papers in this vein argue that a common monetary policy can lead to fiscal spillover effects of independent fiscal policies and thus requires some form of fiscal coordination and restriction. Sibert (1992) for instance shows that a lack of fiscal cooperation with a common monetary policy can lead to a deflationary outcome if governments rely on distortionary taxes and seigniorage income. If seigniorage is set by a common central bank and equally divided among the members of the union, uncoordinated tax policies lead to too high taxes and too little inflation. ${ }^{4}$

Whether more or less fiscal coordination may be required to avoid welfare losses is also discussed in Beetsma and Bovenberg (1998). They show that fiscal coordination actually offsets the disciplining effect that may arise from monetary unification as a larger union containing many non-cooperative fiscal players strengthens the strategic position of a common central bank. In Beetsma and Uhlig (1999) a common monetary policy is discussed in a framework of fiscal policy making where a current government may want to constrain future opposing governments by overspending today. It is shown that a monetary union worsens the political debt bias via the free-riding problem. Therefore, in a monetary union single members will want debt restrictions which they reject with a non-integrated monetary policy. Chari and Kehoe (2007) analyze the necessity of fiscal restrictions comparing monetary policy making with and without commitment. It turns out that without commitment fiscal policy is too expansive in a monetary union as a single country does not face the full marginal costs of such a choice in terms of higher inflation. Only if the monetary policy makers can commit there is no need for fiscal restrictions. Finally, Dixit and Lambertini $(2001,2003)$ argue for the imposition of fiscal constraints if independent national fiscal policy makers and an independent common monetary policy differ in their macroeconomic objectives.

Third, our discussion is related to analyses of a collapse of a nation state or a monetary union. Differences in preference and fiscal motives are often argued to be behind the collapse of nation states or secession of individual regions from a union (Bolton and Roland, 1997). When preferences about the size or mix of publicly provided goods differ, individual regions may not be willing to contribute to financing those goods that they prefer less. The same applies to cases where there is a large element of redistribution of income and purchasing power among regions or nations. Then, a restriction of fiscal redistribution may be needed to ensure the entirety of a nation Fidrmuc (2013). Historical studies of the collapse of monetary unions (Cohen 1993; Dornbusch 1992; Fidrmuc et al. 1999; Nitsch 2005) also stress the importance of fiscal redistribution in addition to political motives. By extension, these arguments also matter in a discussion about a potential collapse of the European Monetary Union (Eichengreen 2010;

\footnotetext{
${ }^{4}$ In an accompanying paper, Sibert (1994) shows that if the central bank does not only choose the level of seigniorage but also its allocation between member states the opposite holds.
} 
Shambaugh et al. 2012).

We build on arguments developed in all of these approaches. The paper closest to our analysis is Beetsma and Bovenberg (2001), who not only look at the interaction of monetary and fiscal policies, but introduce a fiscal transfer scheme which is equal to the one we consider here. Their focus is on the implication of fiscal insurance on fiscal policy making. The authors study a possible trade-off between the stabilizing effect of a fiscal transfer scheme and problems of moral hazard due to asymmetric information about a member country's fiscal discipline. The main finding is that in a monetary union moral hazard may be of less importance because single member countries can expect to a lower extent that the common central bank will loosen monetary policies as a response to fiscal expansion.

The additional aspect that our contribution brings into the picture is a possible dissolution of the union. We add to the discussion the argument that the central bank also has an incentive to maintain a monetary union. Particularly, we argue that the common central bank needs to be seen as an institution that will hardly have an interest in abolishing itself by letting a monetary union collapse. ${ }^{5}$ Commitment to a particular monetary policy making is, therefore, constrained by the fact that central bankers will try to avoid a collapse of the union. While still interested in a low inflation environment, our common central bank will adjust inflation rates in order to avoid a member countries' exit if necessary. With such a common central bank, we argue, the introduction of a fiscal transfer mechanism will feedback on monetary policy making.

\section{The Model}

We consider a monetary union composed of two countries. ${ }^{6}$ Output $y_{i}$ of economy $i=1,2$ follows

$$
y_{i}=\bar{y}_{i}+\pi_{i}-\pi_{i}^{e}-t_{i}-C_{G, i}
$$

with $\pi_{i}$ as inflation, $\pi_{i}^{e}$ as expected inflation, and $t_{i}$ as a distortionary tax rate that lowers potential output $\bar{y}_{i}$ (Alesina and Tabellini 1987; De Kock and Grilli 1993). ${ }^{7}$ In addition, we add potential economic costs or benefits $C_{G, i}$ from leaving the union. There is a vivid discussion about likely benefits from leaving monetary union in terms of being able to devalue and then boost output by increasing exports (Roubini 2011; Sinn 2013). ${ }^{8}$ Others instead stress the negative effects from leaving a monetary union in terms of disrupting trade or financial flows, increased interest rates, or collapsing banking sectors (Buiter 2011; Eichengreen 2010). Rather than modeling all these possible economic

\footnotetext{
${ }^{5}$ This is somewhat related to the discussion initiated by Lohmann (1992) and Moser (1999) that central banks may give in in order not to be overruled by governments. Here as well, monetary policy is endogenous to the threat of losing "face".

${ }^{6}$ The basic equations of the model are derived in the Appendix.

${ }^{7}$ We assume that purchasing power parity holds at all times, so that the real exchange is constant and does not influence output.

${ }^{8}$ Devaluing would also allow to correct an increase in real wages that followed in many countries due to the inability to devalue (see Coudert and Couharde 2009).
} 
mechanisms explicitly we add a term $C_{G, i}$ that changes output when a country leaves the monetary union. Moreover, considering all these arguments, it is very likely that even the countries concerned are not fully aware whether positive or negative effects are stronger. ${ }^{9}$ We thus assume that these exit costs are unknown and could even be negative (that is, output increasing.) Formally, we assume that $C_{G, i}=0$ if the government stays within the monetary union, and $C_{G, i} \neq 0$ if it leaves. These costs are neither known to the government nor to the central bank. We assume $E\left[C_{G, i}\right]=C_{G, i}$ with variance $\sigma_{C_{G, i}}^{2}$.

The government of country $i$ features the following objective function

$$
V_{G, i}=E\left[y_{i}-\frac{\alpha_{i}}{2} \pi_{i}^{2}\right]
$$

That is, we assume the payoff of a government $i$ is increasing linearly in output $y_{i}$ and decreasing (convex) in inflation $\pi_{i}$, as in Alesina (1987), Barro and Gordon (1983) or Persson and Tabellini (1990). Preferences of member states may differ with respect to monetary policy as they could have different degrees of inflation aversion which enter with parameter $\alpha_{i}>0$. Analyzing Eurobarometer data, Scheve (2004) finds, for example, that the citizens of France and Italy have lower, and the citizens of Germany higher, inflation aversion relative to UK respondents. ${ }^{10}$

When choosing their policies governments face budget constraints

$$
\begin{gathered}
\bar{g}_{i}=t_{i}-\varepsilon_{i}+\gamma\left(\varepsilon_{i}-\bar{\varepsilon}\right) \\
\bar{g}_{j}=t_{j}-\varepsilon_{j}+\gamma\left(\varepsilon_{j}-\bar{\varepsilon}\right)
\end{gathered}
$$

with $\bar{\varepsilon}=(1-\theta) \varepsilon_{i}+\theta \varepsilon_{j}$ as an average fiscal shock for the entire union. The relative size of countries is captured by $0<\theta<1$. We assume there is a fiscal shock $\varepsilon$ but fiscal expenditures are fixed. In particular for shorter time horizons, the largest part of government expenditures may be seen as fixed, such as salaries of public employees, social security expenditures and payments on public debts (which we do not explicitly model) (see Beetsma and Bovenberg 2001 or De Kock and Grilli 1993). Given fixed expenditures, government budgets may be positively or negatively affected by unforeseen expenditures or revenues, possibly because of business cycle developments, natural disasters, or military conflicts. These shocks are measured as $\varepsilon_{i, j}$. Tax rates $t_{i, j}$ adjust endogenously to ensure budget balance. All variables are expressed as a share of nominal GDP (see Appendix). ${ }^{11}$

If country $i$ is a member of the union, it receives (pays) a fiscal transfer if its negative fiscal shock is higher (lower) than the average $\bar{\varepsilon}$ within the union.

\footnotetext{
${ }^{9}$ See Cliffe (2010) for an estimation of the economic costs of an EMU break-up under different scenarios. These costs may also stem from the legal uncertainty regarding the (lack of) provisions in the Maastricht treaty as to whether single countries are allowed to exit the Eurozone. For a discussion see, e.g., Athanassiou (2009) or Dammann (2012).

${ }^{10}$ Alesina and Grilli (1993) derive the incentive to join a monetary union when inflation aversion differs among potential member states.

${ }^{11}$ We abstract from seigniorage revenue as a source of finance because such revenues play only a negligible role in advanced economies. In addition, it would change none of our fundamental results.
} 
Of course $\gamma(1-\theta)\left(\varepsilon_{i}-\bar{\varepsilon}\right)+\gamma \theta\left(\varepsilon_{j}-\bar{\varepsilon}\right)=0$, where $\gamma$ is the parameter for the scope of the fiscal transfer scheme.

There is fiscal redistribution depending on the levels of output or income, but fiscal integration takes exclusively the form of an insurance mechanism. While most federations have a combination of both mechanisms, we focus on the insurance motive. The EU, for instance, with its cohesion and structural funds, has a mechanism that allows for transfers from rich to poor countries, independent of any cyclical elements. Our model rather captures aspects of shock insurance as foreseen in the European Financial Stabilization Mechanism (EFSM) and European Stability Mechanism (ESM), possibly because countries cannot (any longer) access capital markets. ${ }^{12}$

The policy instruments available to governments depend on whether they are members of the monetary union or not. Obviously, membership in the monetary union implies giving up monetary autonomy, while at the same time it grants access to the fiscal insurance scheme. Governments have the following policy instruments:

- Within a monetary union, they take the inflation rate (monetary policy) and the fiscal union parameter $\gamma>0$ as given. This yields a payoff for each country of $V_{G}^{c}$, where $C$ denotes the case of policy making in a monetary union.

- Outside of a monetary union each country has control of its own monetary policy setting $\pi_{i}$ given $\gamma=0$. This yields a payoff for each country of $V_{G}^{s}$, where the superscript $S$ denotes the case of independent policy making on a national level. ${ }^{13}$

- The governments compare payoffs and opt out of the monetary union if comparison of payoffs taking into account uncertain $E\left[C_{G}\right]$ dictates so. Exit costs only realize if one of the governments decides to exit.

If the country retains membership in the monetary union, common monetary policy is set by the common central bank. It minimizes the following loss function

$$
V_{C}=\left\{\begin{array}{c}
\pi^{2} \\
\pi_{\text {out }}^{2}+C_{C}
\end{array}\right.
$$

where $C_{C}>0 .{ }^{14}$ Should no country choose to exit the union so that the union persists, the losses of the central bank are $\pi^{2}$. If one of the countries chooses to exit, the central bankers have losses $C_{C}$ accruing from the break down of the union and face inflation losses according to the single countries'

\footnotetext{
${ }^{12}$ The large literature on the need and existence of redistribution mechanisms in a monetary union is surveyed in Bordo et al. (2013), De Grauwe and Ji (2014) and Masson and Taylor (1993).

${ }^{13}$ That is, we suppose that national central banks have the same utility functions and parameters as governments.

${ }^{14}$ See also Moser (1999).
} 
$(i, j)$ chosen inflation rates. If countries leave, union wide inflation is given as $\pi_{\text {out }}=(1-\theta) \pi_{i}^{s}+\theta \pi_{j}^{s}$.

We thus postulate that central bankers suffer from losses arising from the breakdown of a monetary union. This appears reasonable to assume as they would lose jobs and reputation and possibly face accusations of not having been able to save the monetary union. In addition, we assume that central bankers genuinely dislike inflation and would hence suffer from inflation even if it would not be determined by them. In summary, central bankers have two motives to try to ensure persistence of monetary union. One motive follows from their professional and personal interest in keeping inflation low, the other being a bureaucratic interest in, or ego-rent from, running the common central bank.

Finally, the timing of events is the following: (i) inflation expectations and nominal wages are set, (ii) shocks $\varepsilon_{i, j}$ realize, (iii) the common central bank chooses its inflation rate $\pi$, (iv) governments choose whether to stay in the monetary union or to set their monetary policy independently, (v) exit costs (as one of the two governments exits union) occur, a renationalized monetary policy is set, and output realizes. We solve the model by backward induction.

Note that our timing departs from the standard assumption that countries decide before shocks occur and the central bank sets monetary policy (Hefeker, 2003). In this strand of the literature models start from the assumption that countries decide on the entry into monetary union before they know about possible shocks and redistribution. Since we focus on exit, however, and assume that countries are free to leave whenever they want, countries do not have to form expectations about shocks since they always have the option to leave after shocks are realized.

\section{Policy choices}

\subsection{Government decision}

Governments play Nash against each other and take the respective choices of each other as given. When deciding on inflation, inflation expectations have been set and shocks have realized. Exit costs are not known. Then, from the perspective of country $i$ (and similarly $j$ ) exiting yields an expected payoff of

$$
V_{G, i}^{s}=E\left[y_{i}^{s}-\frac{\alpha_{i}}{2} \pi_{i}^{s 2}\right]
$$

with

$$
y_{i}^{s}=\bar{y}_{i}+\pi_{i}^{s}-\pi_{i}^{e}-t_{i}^{s}-E\left[C_{G, i}\right]
$$

and

$$
\bar{g}_{i}=t_{i}^{s}-\varepsilon_{i} .
$$

Staying in the union yields a payoff of

$$
V_{G, i}^{c}=E\left[y_{i}^{c}-\frac{\alpha_{i}}{2} \pi^{2}\right]
$$


with

$$
y_{i}^{c}=\bar{y}_{i}+\pi-\pi_{i}^{e}-t_{i}^{c}
$$

and

$$
\bar{g}_{i}=t_{i}^{c}-\varepsilon_{i}+\gamma\left(\varepsilon_{i}-\bar{\varepsilon}\right)
$$

where, as already introduced earlier, the superscript $S$ denotes the case of independent policy making on a national level, and $C$ denotes the case of policy making in a monetary union, respectively. The two alternatives differ in two important respects. First, in case of exiting from the union, the country experiences expected costs from doing so of $E\left[C_{G, i}\right]$. Second, tax rates will differ because in case of exiting there will be no fiscal redistribution, $\gamma=0$. In case of $\varepsilon_{i}>\bar{\varepsilon}$ this means to forgo financial support, in case of $\varepsilon_{i}<\bar{\varepsilon}$ this means saving an additional expenditure.

The union breaks up if at least one country decides to exit. There could be two reasons for this, either the quest to set monetary policy independently, or the desire to end fiscal redistribution. If the union breaks up, each country will choose its own monetary policy $\pi_{i}$. The choice follows from optimizing (6) under the constraints (7) and (8). The optimal independent monetary policy is

$$
\pi_{i}^{s}=1 / \alpha_{i} .
$$
of

Using (7), (8) and (12) in (6) yields expected utility for the case of exiting

$$
E\left[V_{G, i}^{s}\right]=\bar{y}_{i}+1 / 2 \alpha_{i}-\pi_{i}^{e}-\left(\bar{g}_{i}+\varepsilon_{i}\right)-E\left[C_{G, i}\right] .
$$

Thus, comparing (13) with (9) and using (12) and $\bar{\varepsilon}=(1-\theta) \varepsilon_{i}+\theta \varepsilon_{j}$, yields a critical level of inflation for which country $i$ is indifferent between exiting and staying in the union: ${ }^{15}$

$$
\hat{\pi}_{i}=\pi_{i}^{s}-\frac{1}{\sqrt{\alpha_{i}}} \sqrt{2\left(E\left[C_{G, i}\right]+\gamma\left(\varepsilon_{i}-\bar{\varepsilon}\right)\right)} .
$$

From the point of view of government $i$ the common inflation necessary to ensure continued membership in the union is increasing in inflation set outside the union, falling in the expected costs of exiting from the union and decreasing in fiscal redistribution when the country is a net-receiver $\left(\varepsilon_{i}>\bar{\varepsilon}\right)$. In case it is a net-contributor, inflation in the union has to be higher to compensate the country for the negative output effect of additional taxes. Notice that $\gamma$, the size of the fiscal transfers in response to asymmetric shocks, matters as well as the relative sizes of countries. As $\theta$ is the relative size of country $j$, more generous redistribution benefits smaller countries relatively more and thus lowers the critical rate of inflation.

\footnotetext{
${ }^{15}$ Due to the convex costs of inflation for governments, there are two critical rates of inflation which ensure indifference between exiting and staying in the union. Obviously, an inflation averse central bank would set the lower one if being able to choose. Therefore, we concentrate on the negative solution in what follows.
} 


\subsection{Central bank behavior}

We will derive the central bank's behavior in two steps. First, we will determine the conditions for which the central bank is willing to not let the monetary union break-up $\left(C_{C}>\tilde{C}\right)$. In the step that follows we calculate the monetary policies which are necessary so that members states are discentivized from leaving the union.

\subsubsection{Break-up of monetary union}

Above, we have argued that the central bank has a strong interest in preserving the union. This could be due to a genuine conviction that monetary union is welfare improving and that, therefore, a collapse would bring high costs $\left(C_{C}\right)$. A view more in line with the political economy of rent-seeking would be that the existence of monetary union entails ego-rents, or other rents from holding office for central bankers. Additionally we assume in (5) that central bankers would also suffer from inflation when they are no longer responsible for it, i.e. they suffer from national rates of inflation $\left(\pi_{\text {out }}\right)$ in addition to the loss stemming form the collapse of the union. When deciding whether to set inflation high or low enough to meet the participation constraint of the country closer to exiting the monetary union or to accept collapse of the union, the central bank has to compare the respective losses from each case, as defined in (5). The following proposition summarizes the various decision scenarios for the central bank and yields the conditions under which the central bank will set a monetary policy that induces countries to stay in the union.

\section{Proposition 1:}

1. For symmetric inflation aversion, i.e. $\alpha_{i}=\alpha_{j}$, and heterogeneous countries with respect to expected exit costs $\left(E\left[C_{G}\right]\right)$ and size $(\theta)$, the central bank will set a monetary policy that ensures the existence of the union for any $C_{C} \geq 0$.

2. For asymmetric inflation aversion the central bank will set monetary policy that ensures the existence of the union whenever its costs from a collapse of monetary union are above some critical level $C_{C}>\tilde{C}>0$. This critical level of costs depends on expected exit costs, the fiscal transfer scheme, and the size of countries in the following way.

(a) The critical cost level for the central bank is declining in member states' expected exit costs: $\frac{d \tilde{C}}{d E\left[C_{G}\right]}<0$.

(b) Let $i$ be the country paying into the fiscal transfer scheme. Whether the critical cost level for the central bank increases or decreases in the amount of fiscal insurance depends on whether the central bank has to target country $i$ or $j$ :

i. $\left.\frac{d \tilde{C}}{d \gamma}\right|_{\varepsilon_{j}-\varepsilon_{i}>0}>0$ if $i$ is the critical country, i.e. the country closer to exiting the monetary union, targeted by the central bank. 
ii. $\left.\frac{d \tilde{C}}{d \gamma}\right|_{\varepsilon_{j}-\varepsilon_{i}>0}<0$ if $j$ is the critical country, i.e. the country closer to exiting the monetary union, targeted by the central bank.

(c) Whether the critical cost level increases or decreases in the relative size of country $j$ depends on the relative inflation aversion of countries. A sufficient condition for $\left.\frac{d \tilde{C}}{d \theta}\right|_{\varepsilon_{j}-\varepsilon_{i}>0}>0$ is $\alpha_{i} \leq \alpha_{j}$, otherwise we have $\left.\frac{d \tilde{C}}{d \theta}\right|_{\varepsilon_{j}-\varepsilon_{i}>0} \gtreqless 0$.

Proof: See the Appendix.

With respect to symmetric inflation aversions of the two countries, the central bank will not let collapse the monetary union even if it assigns no costs other than those arising from positive inflation rates to the break-up of the union $\left(C_{C}=0\right)$. The central bank knows that if the monetary union no longer exists both countries will set inflation rates equal to $\pi_{i}^{s}=1 / \alpha_{i}$. Since these rates of inflation are higher than in the monetary union with redistribution, the central bank will always fare better within the monetary union even if its collapse would otherwise be costless.

If inflation aversions are asymmetric and, consequently, inflation rates differ between countries if the union has broken up, the decision problem of the central bank becomes more involved. For sufficiently large exit costs $C_{C}>\tilde{C}$ it will still choose to run a monetary policy that avoids a break down. How high these costs have to be, however, depends on the expected exit costs of member countries' $E\left[C_{G}\right]$, the scope of the fiscal transfer scheme $\gamma$, the relative size of countries $\theta$, and which country is actually paying into the fiscal transfer scheme $\left(\varepsilon_{j}-\varepsilon_{i} \lessgtr 0\right)$. As before, in order to spell out the underlying economic mechanism, we assume that country $i$ is the net-contributor.

It is quite intuitive that critical costs $\tilde{C}$ are lower for the central bank if the member countries expect higher exit costs. If the central bank can be more certain that no member will exit because it is a too costly option to them, it is able to reduce inflation rates to a larger degree without risking that countries will leave. Consequently, the central bankers' self-interest in the monetary union $\left(C_{C}\right)$ has to be less developed.

How the scope of the fiscal insurance scheme $\gamma$ impacts on the critical cost level of the central bank depends on which of the countries is decisive for the survival of monetary union. A country that has to pay the transfer needs to raise taxes to balance its budget. To compensate for the negative output effect of taxes it demands higher inflation, which in turn is increasing in the amount of fiscal redistribution. If the central bank has to address the demands of the netcontributor, inflation is thus increasing in $\gamma$. For the central bank to be willing to set this high inflation to avoid collapse of the monetary union, its losses from collapse must be sufficiently high. If country $j$ is critical for the survival of monetary union, the reverse logic applies. A generous fiscal redistribution leaves this country content with low inflation, which makes it more likely that the central bank is willing to accommodate this demand, even at low costs from a collapse. Therefore, $\tilde{C}$ can be lower. 
Finally, the relative size of the countries matters. Independent of which country is critical for the survival of the monetary union, the relative size $\theta$ of the net-receiving country increases the critical cost level of the central bank. The larger is country $j$, the higher are the distortionary effects from redistribution on country $i$. Consequently, country $i$ will demand a higher inflation to be compensated. For the central bank to be willing to accommodate this high inflation, its costs from a collapse of monetary union have to be sufficiently high. This effect is reinforced by the inflation aversion of country $j$, because a collapse of monetary union would not lead to much higher inflation in country $j$ if this country is very inflation averse. Hence, the expected costs for the central bank in terms of higher inflation outside the monetary union are relatively low, and thus the political costs have to be higher so that the central bank wants to avoid a collapse of monetary union.

\subsubsection{Central bank policy within monetary union}

After having derived the conditions for which the central bank is willing to not let the monetary union break-up $\left(C_{C}>\tilde{C}\right)$, we can determine the monetary policies for the central bank necessary to keep member states from leaving the union. In order to make the monetary union survive, the central bank has to make sure that none of the two countries finds it advantageous to leave the union. Since now the behavior of the countries is binding, additional factors will play a role. Before, when analyzing the circumstances under which the central bank is willing to rescue the union, only inflation aversion mattered as the central bank only cares about inflation (c.f. (5)). The member countries, however, also care for output developments and thus additional factors, such as the scope of fiscal redistribution and expected exist costs, will matter.

The central bank will set a common inflation such that it is at least as large as the critical rate of the country asking for the higher inflation rate to stay in the monetary union, c.f. (14). We summarize the central bank's policy decisions in the following proposition.

Proposition 2: Let $i$ be the country paying into the fiscal transfer scheme and $j$ be the country receiving fiscal transfers. Then inflation rates are determined as follows.

1. If countries are symmetric, the central bank will set the inflation rate to address the needs of the country paying for fiscal transfers. A larger fiscal transfer scheme leads to an expansionary monetary policy.

2. If countries are asymmetric, monetary policy making is affected by a fiscal transfer scheme as follows.

(a) Exit costs: Monetary policy becomes more expansionary with a fiscal transfer scheme if expected exit costs of the country $i$ paying into the fiscal scheme and the country $j$ receiving transfers fulfill $E\left[C_{G, i}\right]-$ $E\left[C_{G, j}\right] \leq \gamma\left(\varepsilon_{j}-\varepsilon_{i}\right)$, and is more restrictive otherwise. 
(b) Inflation aversion: Define the relation between countries' inflation aversion as $k=\alpha_{j} / \alpha_{i}$. There is a critical ratio $\widetilde{k}$, such that for all values $k>\tilde{k}$, the central bank has to ensure that the net-paying country $i$ does not leave the monetary union. For $0<k<\tilde{k}$, country $j$ is the one closer to exiting the union and common monetary policy must be set to meet its requirements. For all $k>\tilde{k}$ monetary policy becomes more expansionary while it becomes more contractionary for all $0<k<\tilde{k}$ with a fiscal transfer scheme.

(c) The effect of the fiscal transfer scheme on monetary policy is reinforced by a relatively larger sized country $j$ if the central bank sets inflation to address the needs of country $i$ and moderated if it targets country $j$.

Proof: See the Appendix.

In Figure 1 we illustrate the various cases with a numerical example. We plot the differences in payoffs for a country being in a monetary union and subject to a common monetary policy, and being outside of a monetary union setting its own monetary policy. The country paying the transfer is color coded black, and the dashed black lines refer to the country receiving the transfer. In panels (a) and (b) we vary the expected exit costs such that the country paying the transfer has relatively lower or higher costs of exiting the union, respectively. In panels (c) and (d) inflation aversion between countries differs. In panel (c) the paying country has lower inflation aversion, and in panel (d) the paying country has a higher inflation aversion than the country receiving the transfer. Black dots indicate the optimal central bank policy. Given that it prefers to not let the union break-up (see Proposition 1), it will choose an inflation rate as low as possible but not too low to let any of the two countries choose to exit the union. This is due to the following underlying economic mechanisms.

As stated before, the country paying the transfers has to increase taxes and requires higher inflation to balance the negative output effect. Up to the point where the central bank wants to secure the existence of the monetary union, it will address the needs of this country and inflation is thus increasing in the size of the fiscal transfer scheme. It should be noted that in this case the country receiving the fiscal transfers is subject to the same common and expansionary monetary policy. There is a spill-over arising from the common monetary policy which will further boost its output although the monetary policy was rather installed to keep the country paying into the fiscal transfer scheme within the union.

Results derived for a symmetric union are not necessarily identical to the case of an asymmetric union. As can be seen from Figure 1 the critical inflation rate that prevents a country from leaving the union, may it be a contributor or a receiver of the fiscal transfer, shifts as a response to changes in expected exit costs and inflation aversions.

Should the paying country have lower exit costs than the country receiving the fiscal transfer, the central bank will cater to the contributing country by 
loosening its monetary stance. On the other hand, if the giving country has sufficiently high exit costs, the central bank will expect that this country stays in the union even if the burden of financing the fiscal transfers are relatively high. The exit decision of the receiving country becomes the binding constraint for the common monetary policy (panel b). From the point of view of that country, the fiscal transfers and an expansionary monetary policy are substitutes. To the extent that it receives the transfer from the other country, it prefers a more restrictive monetary policy.

Turning to differences in inflation aversion, we find that the central bank has to take the participation constraint of the paying country as binding if its inflation aversion is sufficiently low relative to the inflation aversion of the other country in the monetary union. The intuition is similar as before: if country $i$ is net-payer it wishes to be compensated for this additional expense by a more expansive monetary policy. This is the case unless the country is extremely inflation averse. At the same time, country $j$, even if it is more inflation averse than country $i$, is willing to accept higher inflation as a price for being supported through a fiscal transfer from country $i$.

Finally, the relative size of countries matters for the effect of fiscal transfers on monetary policy decisions. The larger is country $j$, the higher are the distortionary effects from redistribution on country $i$ should this country be paying into the transfer scheme and be critical for survival of the monetary union. Consequently, it will demand an even higher inflation to be compensated. Should country $j$ be critical, however, the monetary policy will be less contractionary in reaction to the fiscal transfer scheme with a larger sized country $j$. While the fiscal transfer is still a substitute for an expansionary policy, a larger sized country $j$ receives lower transfers out of the fiscal insurance scheme which, in turn, needs to be taken into account by the central bank to avoid an exit of country $j$.

\section{Conclusion}

In the aftermath of the financial and sovereign debt crises European policymakers are striving for policy measures accompanying and improving the functioning of the Stability and Growth Pact. On top of the already implemented reforms, a recurring proposal is to install a fiscal transfer scheme for the member countries that smoothens asymmetric shocks. Such fiscal transfer schemes have been analyzed from the perspective of that they may redistribute income and cause problems of moral hazard on top of providing insurance to the pool of insured members. So far, little to no attention has been given to the question how such a transfer scheme may feedback on monetary policy making when a central bank has a vested interest not to let the monetary union break apart.

We build a model of a monetary union with a central bank and two heterogeneous member states linked by a fiscal transfer scheme to study the repercussions of the insurance mechanism on monetary policy making. Our results

suggest that the common monetary policy may go either way, become more or 


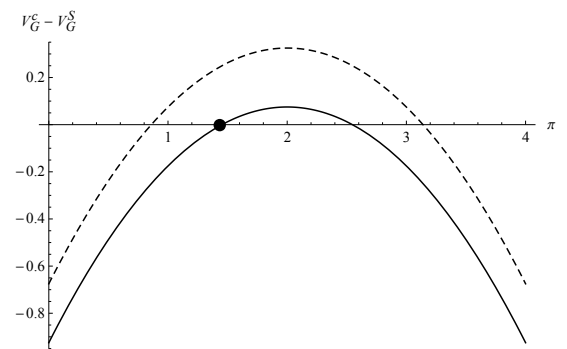

(a)

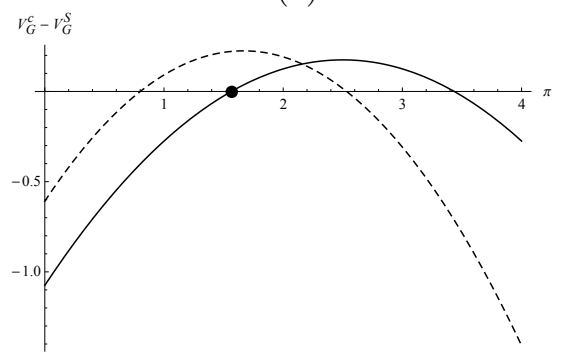

(c)

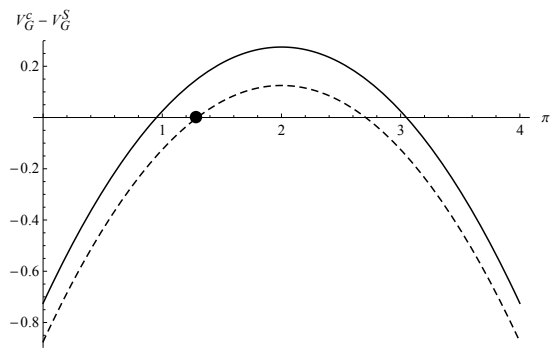

(b)

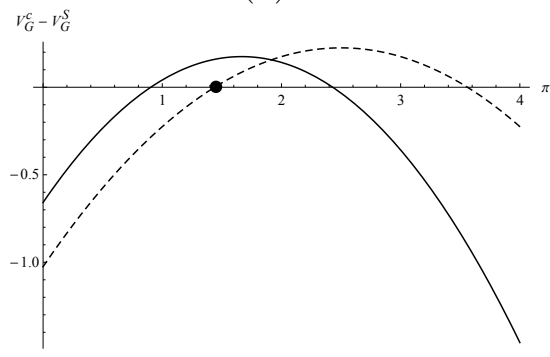

(d)

Figure 1: Government payoff functions over inflation rates for (a) paying country having relatively lower exit costs, (b) paying country having relatively higher exit costs, (c) paying country having relatively lower inflation aversion, (d) paying country having relatively higher inflation aversion. Coding: black lines refer to country paying the transfer, country receiving the transfer in dashed black. Black dots indicate optimal central bank policy. Parameters: $C_{G}=0.1$ (low exit costs), $C_{G}=0.3$ (high exit costs), $\alpha=0.4$ (low inflation aversion), $\alpha=0.6$ (high inflation aversion), $\gamma=0.5, \epsilon_{i, j}-\bar{\epsilon}= \pm 0.05$ 
less expansionary as one increases the scale of insurance. Which reaction of the central bank one should expect depends on the type of country that the monetary policy maker has to target in order to avoid a break-up of the union. In a homogenous union, the country targeted by the central bank will be the country paying into the transfer scheme. This country wants to be compensated for the distortionary effects arsing from the tax financing of its transfer payments. The country will want to be compensated through higher inflation rates or it will exit the union, and the central bank policy is tailored to suit this country. In a heterogeneous monetary union, the introduction of a fiscal transfer scheme causes a more expansionary monetary policy only if the giving country has lower expected exit costs or a lower inflation aversion than the country receiving the transfer. Monetary policy becomes more restrictive with a fiscal transfer scheme if the giving country has sufficiently high expected exit costs or sufficiently high inflation aversion. These findings may also be interpreted as going against the general perception where a common central bank targets average inflation in a union. Here, the weights given to the national inflation rates when calculating the average aggregate change endogenously depending on the fiscal transfer scheme, exit costs, and aversion to inflation of the different member states.

Although we motivated our setup with van Rompuy's statement on the possible need of a fiscal insurance scheme, our model does not reflect the current EMU because a such a scheme does not exist presently. Actually, we deliberately opted for a more general approach addressing potential repercussions of a fiscal insurance scheme in a monetary union on a common monetary policy. Nevertheless, we believe that our analysis may be taken as a starting point for an alternative interpretation for the current policy of the European Central Bank (ECB).- It sees in it the attempt of the ECB to accommodate the stronger member states who fiscally support crisis states. An expansive monetary policy supports as much those countries that face larger transfer burdens and helps them to compensate for the larger negative output effects of fiscal transfers. This is necessary to reduce the fiscal burden in order to avoid that those countries leave the monetary policy. Our model establishes the conditions for when which of the two (groups of) countries, those paying and those receiving fiscal transfers, must be accommodated by the common central bank to avoid a break-up of monetary union.

There are several possible extensions for future work. One interesting factor would be not only to focus on fiscal insurance but introduce income compensating redistribution. In this case, some countries might expect to be netcontributors at all times and, hence, be compensated through monetary policy. Bringing this together with insurance aspects might yield some interesting interaction between income levels and shock insurance. Another extension would be to look at a larger number of heterogeneous countries. Presumably, this would lead to an even richer set of results as the specific characteristics of the country most likely to exit the union and, therefore, targeted by the common central bank may depend on an even larger number of conditions. 


\section{Acknowledgements:}

We would like to thank our two referees for their helpful comments and suggestions.

\section{Appendix A: Derivation of model}

Output equation:

The derivation of the output equation follows Alesina and Tabellini (1987) and Beetsma and Bovenberg (2001). A representative firm's profits are given as

$$
\text { Max } P(1-t) Y-W N
$$

with $P$ as prices, $Y$ being output, $W$ as the nominal wage, and a production function in labor $N$ following $Y=N^{\eta}$ with $0<\eta<1$. The firm is taxed on revenues and is a price taker on product and labor markets. Optimal labor input follows from the first order condition

$$
P(1-t) N^{\eta-1} \eta-W=0 .
$$

Substituting out labor $N$ with the production function and taking logarithms gives

$$
\ln P+\ln (1-t)+\frac{\eta-1}{\eta} \ln Y+\ln \eta=\ln W .
$$

With $\ln (1-t) \approx-t, \ln P \equiv p, \ln Y \equiv y, \ln W \equiv w$, and setting $\eta=1 / 2$ we get

$$
y=\ln \eta+p-w-t .
$$

Assuming that a trade union wishes to achieve a desired real wage $(v)$, i.e. $v=w-p^{e}$ (see also Alesina and Tabellini, 1987) the output equation becomes

$$
y=\ln \eta+p-p^{e}-v-t .
$$

with $p^{e}$ being the logarithm of the expected price level. Using $\pi_{t}=p_{t}-p_{t-1}$ and $\pi_{t}^{e}=p_{t}^{e}-p_{t-1}$ as definitions of the inflation and the expected inflation rate, respectively, the output equation becomes

$$
y=\ln \eta+\pi-\pi^{e}-v-t
$$

which can be rewritten as, with $\bar{y}$ as the potential output,

$$
y=\bar{y}+\pi-\pi^{e}-t .
$$

Government budget constraint:

Government spending $\bar{G}$ has to be covered by tax revenues but is subject to a fiscal shock $E_{t}$ and possibly fiscal redistribution $\gamma\left(E_{i}-\bar{E}_{t}\right)$ :

$$
\bar{G}=t P Y-E+\gamma\left(E_{i}-\overline{\bar{E}}\right)
$$


Dividing both sides by nominal output, government spending over output has to fulfill

$$
\bar{g}=t-\varepsilon_{i}+\gamma\left(\varepsilon_{i}-\bar{\varepsilon}\right) .
$$

\section{Appendix B: Proofs}

Proof of Proposition 1:

Part 1: That the central bank will not let the monetary union break up can easily be seen from comparing its costs:

$$
\left[\pi_{i, j}^{s}-\frac{1}{\sqrt{\alpha_{i, j}}} \sqrt{2\left(E\left[C_{G, i, j}\right]+\gamma\left(\varepsilon_{i, j}-\bar{\varepsilon}\right)\right)}\right]^{2}<\left[(1-\theta) \pi_{i}^{s}+\theta \pi_{j}^{s}\right]^{2}+C_{C}
$$

where the left hand side of the inequality are the costs arising within a monetary union for the central bank, and the right hand side constitutes the costs for the central bank of a break-up. Due to the equal inflation aversion, and $\pi_{i}=\pi_{j}$, we can also write

$$
\left[\pi^{s}-\frac{1}{\sqrt{\alpha}} \sqrt{2\left(E\left[C_{G, i, j}\right]+\gamma\left(\varepsilon_{i, j}-\bar{\varepsilon}\right)\right)}\right]^{2}<\left[\pi^{s}\right]^{2}+C_{C}
$$

which is fulfilled for any $C_{C} \geq 0$.

Part 2: Define a critical level below which the central bank lets the union collapse. This critical $\widetilde{C}$ is defined by

$$
\left[\pi_{i, j}^{s}-\frac{1}{\sqrt{\alpha_{i, j}}} \sqrt{2\left(E\left[C_{G, i, j}\right]+\gamma\left(\varepsilon_{i, j}-\bar{\varepsilon}\right)\right)}\right]^{2}-\left[(1-\theta) \pi_{i}^{s}+\theta \pi_{j}^{s}\right]^{2}-\tilde{C}=0
$$

where $\bar{\varepsilon}=\theta \varepsilon_{j}+(1-\theta) \varepsilon_{i}$.

Using the implicit function theorem, we get from (25)

$$
\frac{d \tilde{C}}{d E\left[C_{G, i, j}\right]}<0 .
$$

The partial effects of changes in the size of the fiscal transfer scheme and the size of countries on the critical level $\tilde{C}$ are given as

$\frac{d \tilde{C}}{d \gamma}=-\left[\pi_{i, j}^{s}-\frac{1}{\sqrt{\alpha_{i, j}}} \sqrt{2\left(E\left[C_{G, i, j}\right]+\gamma\left(\varepsilon_{i, j}-\bar{\varepsilon}\right)\right)}\right]\left(\frac{1}{\sqrt{\alpha_{i, j}}} \frac{\varepsilon_{i, j}-\bar{\varepsilon}}{\sqrt{2\left(E\left[C_{G, i, j}\right]+\gamma\left(\varepsilon_{i, j}-\bar{\varepsilon}\right)\right)}}\right)$

and

$$
\begin{gathered}
\frac{d \tilde{C}}{d \theta}=\left[\pi_{i, j}^{s}-\frac{1}{\sqrt{\alpha_{i, j}}} \sqrt{2\left(E\left[C_{G, i, j}\right]+\gamma\left(\varepsilon_{i, j}-\bar{\varepsilon}\right)\right)}\right] \frac{1}{\sqrt{\alpha_{i, j}}} \frac{\gamma \partial\left(\varepsilon_{i, j}-\bar{\varepsilon}\right) / \partial \theta}{\sqrt{2\left(E\left[C_{G, i, j}\right]+\gamma\left(\varepsilon_{i, j}-\bar{\varepsilon}\right)\right)}} \\
+2\left[(1-\theta) \pi_{i}^{s}+\theta \pi_{j}^{s}\right]\left(\pi_{i}^{s}-\pi_{j}^{s}\right)
\end{gathered}
$$

As before, we assume that country $i$ is the one paying into the transfer scheme $\left(\varepsilon_{j}-\varepsilon_{i}>0\right)$. 
- If country $i$ is the critical one in the sense that the central bank has to ensure it will not leave the monetary union, we get

$$
\begin{gathered}
\left.\frac{d \tilde{C}}{d \gamma}\right|_{\varepsilon_{j}-\varepsilon_{i}>0}>0 \\
\left.\frac{d \tilde{C}}{d \theta}\right|_{\varepsilon_{j}-\varepsilon_{i}>0}=\left[\pi_{i}^{s}-\frac{1}{\sqrt{\alpha_{i}}} \sqrt{2\left(E\left[C_{G, i}\right]-\gamma \theta\left(\varepsilon_{j}-\varepsilon_{i}\right)\right)}\right] \frac{1}{\sqrt{\alpha_{i}}} \frac{\gamma\left(\varepsilon_{j}-\varepsilon_{i}\right)}{\sqrt{2\left(E\left[C_{G, i}\right]+\gamma\left(\varepsilon_{i}-\bar{\varepsilon}\right)\right)}} \\
+2\left[(1-\theta) \pi_{i}^{s}+\theta \pi_{j}^{s}\right]\left(\pi_{i}^{s}-\pi_{j}^{s}\right)
\end{gathered}
$$

A sufficient condition for $\left.\frac{d \tilde{C}}{d \theta}\right|_{\varepsilon_{j}-\varepsilon_{i}>0}>0$ is $\alpha_{i} \leq \alpha_{j}$, otherwise we have $\left.\frac{d \tilde{C}}{d \theta}\right|_{\varepsilon_{j}-\varepsilon_{i}>0} \gtreqless 0$.

- If country $j$ is the critical one in the sense that the central bank has to ensure it will not leave the monetary union, we have instead

$$
\begin{gathered}
\left.\frac{d \tilde{C}}{d \gamma}\right|_{\varepsilon_{j}-\varepsilon_{i}>0}<0 \\
\left.\frac{d \tilde{C}}{d \theta}\right|_{\varepsilon_{j}-\varepsilon_{i}>0}=\left[\pi_{j}^{s}-\frac{1}{\sqrt{\alpha_{j}}} \sqrt{2\left(E\left[C_{G, j}\right]+\gamma(1-\theta)\left(\varepsilon_{j}-\varepsilon_{i}\right)\right)}\right] \frac{1}{\sqrt{\alpha_{j}}} \frac{\gamma\left(\varepsilon_{j}-\varepsilon_{i}\right)}{\sqrt{2\left(E\left[C_{G, j}\right]+\gamma\left(\varepsilon_{j}-\bar{\varepsilon}\right)\right)}} \\
+2\left[(1-\theta) \pi_{i}^{s}+\theta \pi_{j}^{s}\right]\left(\pi_{i}^{s}-\pi_{j}^{s}\right)
\end{gathered}
$$

A sufficient condition for $\left.\frac{d \tilde{C}}{d \theta}\right|_{\varepsilon_{j}-\varepsilon_{i}>0}>0$ is $\alpha_{i} \leq \alpha_{j}$, otherwise we have $\left.\frac{d \tilde{C}}{d \theta}\right|_{\varepsilon_{j}-\varepsilon_{i}>0} \gtreqless 0$.

Proof of Proposition 2: We first look into the case of symmetric countries and then into the case of asymmetric countries. For each of the cases the critical inflation rate is derived first. Then the sign of the partial derivative with respect to $\gamma$ is determined.

Part 1: Symmetric countries

The critical inflation rate for the paying country $i$ to which the central bank caters because $\hat{\pi}_{i}>\hat{\pi}_{j}$ is

$$
\hat{\pi}_{i}=\pi^{s}-\frac{1}{\sqrt{\alpha}} \sqrt{2\left(E\left[C_{G, i}\right]+\gamma\left(\varepsilon_{i}-\bar{\varepsilon}\right)\right)} .
$$

so that $\frac{\partial \hat{\pi}_{i}}{\partial \gamma}>0$.

Part 2: Asymmetric countries

- Exit costs differ (Proposition 2 (a)): The central bank will cater to the country $i$ paying the transfer if

$$
\pi_{i}^{s}-\frac{1}{\sqrt{\alpha}} \sqrt{2\left(E\left[C_{G, i}\right]+\gamma\left(\varepsilon_{i}-\bar{\varepsilon}\right)\right)} \geq \pi_{j}^{s}-\frac{1}{\sqrt{\alpha}} \sqrt{2\left(E\left[C_{G, j}\right]+\gamma\left(\varepsilon_{j}-\bar{\varepsilon}\right)\right)} .
$$


As $\pi_{i}^{s}=\pi_{j}^{s}$ we have

$$
E\left[C_{G, i}\right]-E\left[C_{G, j}\right] \leq \gamma\left(\varepsilon_{j}-\varepsilon_{i}\right) .
$$

As the right hand side of inequality (35) is positive it is always fulfilled for $E\left[C_{G, i}\right]<E\left[C_{G, j}\right]$. It follows that $\frac{\partial \hat{\pi}}{\partial \gamma}>0$ and, as $\varepsilon_{i}-\bar{\varepsilon}=-\theta\left(\varepsilon_{j}-\varepsilon_{i}\right)$, $\frac{\partial^{2} \hat{\pi}_{i}}{\partial \theta \partial \gamma}>0$. For the difference in exit costs being sufficiently large (35) is not fulfilled. It follows that $\frac{\partial \hat{\pi}_{j}}{\partial \gamma}<0$ and $\frac{\partial^{2} \hat{\pi}_{j}}{\partial \theta \partial \gamma}>0$ because $\varepsilon_{j}-\bar{\varepsilon}=$ $(1-\theta)\left(\varepsilon_{j}-\varepsilon_{i}\right)$.

- Inflation aversions and sizes of countries differ (Propositions 2 (b) and (c)): The central bank will cater to the country $i$ paying the transfer if

$$
\pi_{i}^{s}-\frac{1}{\sqrt{\alpha_{i}}} \sqrt{2\left(E\left[\tilde{C}_{G}\right]+\gamma\left(\varepsilon_{i}-\bar{\varepsilon}\right)\right)} \geq \pi_{j}^{s}-\frac{1}{\sqrt{\alpha_{j}}} \sqrt{2\left(E\left[\tilde{C}_{G}\right]+\gamma\left(\varepsilon_{j}-\bar{\varepsilon}\right)\right)}
$$

with $\pi_{i}^{s}=1 / \alpha_{i}$ and $\pi_{j}^{s}=1 / \alpha_{j}$. Furthermore, notice that $\varepsilon_{i}-\bar{\varepsilon}=$ $-\theta\left(\varepsilon_{j}-\varepsilon_{i}\right)$ and $\varepsilon_{j}-\bar{\varepsilon}=(1-\theta)\left(\varepsilon_{j}-\varepsilon_{i}\right)$. Using these expressions and rearranging yields

$\frac{\alpha_{j}-\alpha_{i}}{\sqrt{\alpha_{i} \alpha_{j}}} \geq \sqrt{\alpha_{j}} \sqrt{2\left(E\left[\tilde{C}_{G}\right]-\gamma \theta\left(\varepsilon_{j}-\varepsilon_{i}\right)\right)}-\sqrt{\alpha_{i}} \sqrt{2\left(E\left[\tilde{C}_{G}\right]+\gamma(1-\theta)\left(\varepsilon_{j}-\varepsilon_{i}\right)\right)}$.

To simplify, we define $\alpha_{j}=k \alpha_{i}$ and $\alpha_{i}=\alpha$. For all $\alpha_{i, j}>0$ it must be that $k>0$. Then, we get

$$
\frac{(k-1)}{\sqrt{k \alpha}} \geq \sqrt{k} \sqrt{2\left(E\left[\tilde{C}_{G}\right]-\gamma \theta\left(\varepsilon_{j}-\varepsilon_{i}\right)\right)}-\sqrt{2\left(E\left[\tilde{C}_{G}\right]+\gamma(1-\theta)\left(\varepsilon_{j}-\varepsilon_{i}\right)\right)} .
$$

For $k<1$, the left hand side (lhs) of inequality (38) is negative. Furthermore, $\left.l h s\right|_{k=1}=0$ and $\left.l h s\right|_{k \rightarrow 0}=-\infty$. The $l h s$ is concave in $k$, see Figure 2

- Let $\gamma=0$ be at the moment. Then, the right hand side (rhs) of inequality (38) is negative for all $\sqrt{k}<1$, and $\left.r h s\right|_{k=1}=0$. Furthermore, we have $\left.r h s\right|_{k=0}=-\sqrt{2 E\left[\tilde{C}_{G}\right]}$. Finally, the $r h s$ is concave in $k$, too. Given that both, lhs and $r h s$ are concave, and that $\left.l h s\right|_{k=1}=\left.r h s\right|_{k=1}=0$, and $\left.l h s\right|_{k \rightarrow 0}<\left.r h s\right|_{k=0}$, it follows that lhs $>$ rhs for all $k>1$, which is equivalent to $\alpha_{j}>\alpha_{i}$.

- For the general case of $\gamma>0$ the first term on the rhs is smaller than the second term for moderate values of $k$. This difference is larger the larger is the difference between $\varepsilon_{j}$ and $\varepsilon_{i}$, the larger is the reaction to the size differences in shocks $\gamma$, and the larger is $\theta$, the relative size of country $j$. That is, $\left.r h s\right|_{k=0}<-\sqrt{2 E\left[\tilde{C}_{G}\right]}$ now, and it is negative 


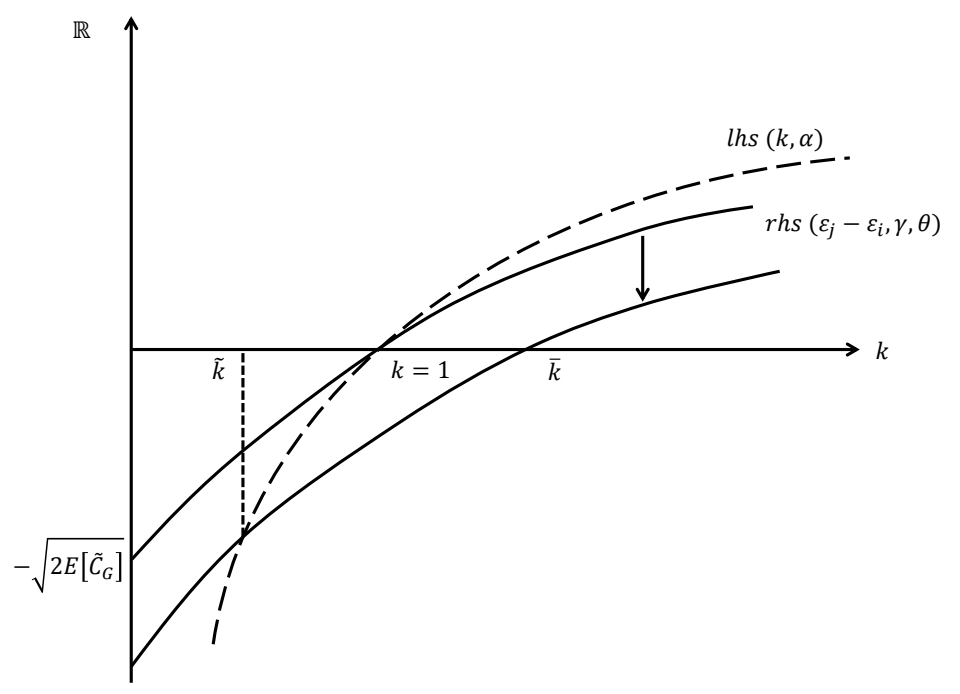

Figure 2: Plot of condition (38)

until $k$ reaches some $\bar{k}>1$ and, thus, overcompensates the influence of $\varepsilon$ and $\gamma$. As $\left.l h s\right|_{k \rightarrow 0}=-\infty$ both curves will intersect for some value $\tilde{k}<1$. This $\widetilde{k}$ is declining in $\varepsilon_{j}-\varepsilon_{i}, \gamma$ and $\theta$. It follows that the central bank obeys the participation constraint of country $i$ for all values of $k>\tilde{k}$. Thus, we have $\frac{\partial \hat{\pi}_{i}}{\partial \gamma}>0$, and $\frac{\partial^{2} \hat{\pi}_{i}}{\partial \theta \partial \gamma}>0$.

\section{References}

Alesina, A. (1987): "Macroeconomic policy in a two-party system as a repeated game," The Quarterly Journal of Economics, 102, 651-678.

Alesina, A. AND V. GRILli (1993): "On the feasibility of a one-speed or multispeed European Monetary Union," Economics and Politics, 5, 145-165.

Alesina, A. And G. Tabellini (1987): "Rules and discretion with noncoordinated monetary and fiscal policies," Economic Inquiry, 25, 619-630.

Athanassiou, P. (2009): "Withdrawal and expulsion from the EU and EMU: Some reflections," ECB Legal Working Paper No. 10.

Bargain, O., M. Dolls, C. Fuest, D. Neumann, A. Peichl, N. PesTEL, AND S. Siegloch (2013): "Fiscal union in Europe? Redistributive and stabilizing effects of a European tax-benefit system and fiscal equalization mechanism," Economic Policy, 28, 375-422. 
BARro, R. AND D. Gordon (1983): "A positive theory of monetary policy in a natural rate model," Journal of Political Economy, 91, 589-610.

Bayoumi, T. And P. R. MAsson (1995): "Fiscal flows in the United States and Canada: lessons for monetary union," European Economic Review, 39, 253-274.

Beetsma, R. M. W. J. And A. L. BovenberG (1998): "Monetary union without fiscal coordination may discipline policymakers," Journal of International Economics, 45, 239-258.

(2001): "The optimality of a monetary union without a fiscal union," Journal of Money, Credit, and Banking, 33, 179-204.

Beetsma, R. M. W. J. And M. Giuliodori (2010): "The macroeconomic costs and benefits of the EMU and other monetary unions: an overview of recent research," Journal of Economic Literature, 48, 603-641.

Beetsma, R. M. W. J. And H. Uhlig (1999): "An analysis of the Stability and Growth Pact," Economic Journal, 109, 546-571.

Bolton, P. And G. Roland (1997): "The breakup of nations: a political economy analysis," The Quarterly Journal of Economics, 112, 1057-1090.

Bordo, M. D., L. Jonung, And A. Markiewicz (2013): "A fiscal union for the Euro: Some lessons from history," CESifo Economic Studies, 59, 449-488.

Buiter, W. (2011): "The Terrible Consequences of a Eurozone Collapse," Financial Times, December 8.

Chari, V. V. And P. Kehoe (2007): "On the need for fiscal constraints in a monetary union," Journal of Monetary Economics, 54, 2399-2408.

Cliffe, M. (2010): "EMU Break-up: Quantifying the Unthinkable," ING, Global Economics, July 7.

Cohen, B. J. (1993): "Beyond EMU: the problem of sustainability," Economics and Politics, 5, 187-203.

Coudert, V. And C. Couharde (2009): "Currency misalignments and exchange rate regimes in emerging and developing countries," Review of International Economics, 17, 121-136.

Dammann, J. C. (2012): "The right to leave the Eurozone," Texas International Law Journal, 48, 125-155.

De Grauwe, P. And Y. Ji (2014): "How much fiscal discipline in a monetary union?" Journal of Macroeconomics, 39, 348-360.

De KocK, G. And V. GRILli (1993): "Fiscal policies and the choice of exchange rate regime," The Economic Journal, 347-358. 
Dixit, A. AND L. LAmbertini (2001): "Monetary-fiscal policy interactions and commitment versus discretion in monetary union," European Economic Review, 45, 977-987.

- (2003): "Symbiosis of monetary and fiscal policies in a monetary union," Journal of International Economics, 60, 235-247.

Dornbusch, R. (1992): "Monetary problems of post-communism: Lessons from the end of the Austro-Hungarian Empire," Review of World Economics, $128,391-424$.

Eichengreen, B. (1990): "One money for Europe? Lessons from the US currency union," Economic Policy, 10, 117-187.

(2010): "The breakup of the Euro Area," in Europe and the Euro, ed. by A. Alesina and F. Giavazzi, University of Chicago Press, 11-51.

Fidrmuc, J. (2013): "Political Economy of Fiscal Unions," CESifo working paper 4344 .

Fidrmuc, J., J. Horvath, AND J. Fidrmuc (1999): "The stability of monetary unions: Lessons from the breakup of Czechoslovakia," Journal of Comparative Economics, 27, 753-781.

Goodhart, C. A. E. (1998): "The two concepts of money: implications for the analysis of optimal currency areas," European Journal of Political Economy, 14, 407-432.

Hefeker, C. (2003): "Federal monetary policy," The Scandinavian Journal of Economics, 105, 643-659.

Kenen, P. B. (1969): "The Theory of Optimum Currency Areas: An Eclectic View," in Monetary Problems of the International Economy, ed. by R. Mundell and A. Swoboda, Chicago: University of Chicago Press, 41-60.

Lohmann, S. (1992): "Optimal commitment in monetary policy: credibility versus flexibility," The American Economic Review, 82, 273-286.

Masson, P. R. And M. P. TAylor (1993): "Fiscal policy within common currency areas," Journal of Common Market Studies, 31, 29-44.

Moser, P. (1999): "Checks and balances, and the supply of central bank independence," European Economic Review, 43, 1569-1593.

NiTsch, V. (2005): "Have a break, have a ... national currency: when do monetary unions fall apart?" in Prospects for Monetary Unions after the Euro, ed. by P. de Grauwe and J. Melitz, Cambridge: MIT Press, 319-345.

Persson, T. And G. TABellini (1990): Macroeconomic policy, credibility and politics, Harwood Academic Publishers. 
(1996a): "Federal and fiscal constitutions: Risk sharing and moral harzard," Econometrica, 64, 623-646.

(1996b): "Federal and fiscal constitutions: Risk sharing and redistribution," Journal of Political Economy, 104, 979-1009.

Roubini, N. (2011): "The Eurozone Is Heading for Break-up," Financial Times, June 13.

SAla-I-Martin, X. AND J. SACHS (1991): "Fiscal federalism and optimum currency areas: evidence for Europe from the United States," NBER Working Paper 3855.

Scheve, K. (2004): "Public inflation aversion and the political economy of macroeconomic policymaking," International Organization, 58, 1-34.

Shambaugh, J. C., R. Reis, And H. Rey (2012): "The Euro's Three Crises [with Comments and Discussion]," Brookings Papers on Economic Activity, $157-231$.

Sibert, A. (1992): "Government finance in a common currency area," Journal of International Money and Finance, 11, 567-578.

(1994): "The allocation of seigniorage in a common curreny area," Journal of International Economics, 37, 111-122.

Sinn, H.-W. (2013): "It is Wrong to Portray Germany as the Euro Winner," Financial Times, 23.

Tavlas, G. S. (2009): "Optimum-currency-area paradoxes," Review of International Economics, 17, 536-551.

Von Hagen, J. (1991): "A note on the empirical effectiveness of formal fiscal restraints," Journal of Public Economics, 44, 199-210. 